\title{
Introducing a flat ontology into landscape research: a case study of water governance experiments in South Africa
}

\author{
Jakob Raffn (D) Andreas Aagaard Christensen - Marlene de Witt • \\ Cathie Lewis · Charon Büchner-Marais
}

Received: 20 August 2020/ Accepted: 8 November 2021

(C) The Author(s), under exclusive licence to Springer Nature B.V. 2021

\begin{abstract}
Context Contemporary resource management paradigms within the developed world build on an understanding of human agency as ontologically distinct from the mode of existence of plants and animals. Because of this perspective, which gives priority to human agency, policies typically take their point of departure with human societies and associated ecosystems deemed of particular value.
\end{abstract}

Supplementary Information The online version contains supplementary material available at https://doi.org/10.1007/ s10980-021-01374-9.

\section{J. Raffn $(\bowtie)$}

Division for Quantitative Sustainability Assessment,

Technical University of Denmark, 2800 Kongens Lyngby,

Denmark

e-mail: jakob.raffn@politicsofnature.org

A. A. Christensen

Department of Geosciences and Natural Resource

Management, University of Copenhagen,

1958 Copenhagen, Denmark

\section{A. A. Christensen}

Department of Geography, Ghent University, 9000 Ghent, Belgium

M. de Witt · C. Büchner-Marais

Water Institute, Stellenbosch University, Stellenbosch, South Africa
Objectives As an alternative to this worldview, social theorists have introduced what is known as "flat ontology", where all beings are bestowed equal rights to negotiate their existence. To explore the implications of introducing such an understanding into landscape management, a participatory planning process for water allocation was developed and tested in a case study in the Eerste River Catchment in South Africa.

Methods The planning process was mediated using the approach "politics of nature" (PoN), which aims to operationalize flat ontology to renegotiate water allocation based on the needs of all beings instead of

\author{
C. Lewis \\ Independent Researcher, Port Elizabeth, South Africa \\ C. Büchner-Marais \\ Centre for Complex Systems in Transition (CST), \\ Stellenbosch University, Stellenbosch, South Africa
}


the desire of a subset of humans. PoN allowed participants to playfully co-develop a common ontology and value-set. Data documenting these processes were collected digitally and analysed.

Results Results indicate that the approach engendered a rethinking of key relationships between human agency and ecosystem functionality, illustrating a potential for PoN-approaches to be deployed for governance of complex landscapes.

Conclusions On the basis of experiments using PoNmethodology in the context of watershed management, it is discussed how the introduction of a flat ontology in landscape research, could inspire new ways of designing and intervening with collaborative resource management processes.

Keywords Environmental sustainability - Political ontology · Integrated water resource management . Actor network theory - Collaborative planning . Politics of nature (PoN)

\section{Introduction}

Freshwater systems are vital for all terrestrial organisms (Dayton 2019) and deliver a broad package of ecosystem services necessary for the survival, wellbeing and prosperity of human populations (Albert et al. 2020). As such, freshwater flow networks and reservoirs constitute a necessary ecological resource for maintaining and improving the functionality of important ecosystems globally, both considered from a socioeconomic perspective (Boretti and Rosa 2019), and from a biodiversity conservation perspective (He et al. 2019). In a landscape ecological perspective, global river systems are of particular interest because they link upstream landscapes with riparian and aquatic habitat areas, human settlements depending on water for land use and recipient water bodies. As such, river systems and associated habitats form an ecological zone linking human settlements spatially and functionally with populations of other organisms (Brierley 2020). In this sense rivers are meeting places between organisms, which depend on the same water resources (Erös and Lowe 2019). Additionally, due to the high species richness of freshwater ecosystems (Tickner et al. 2020) in combination with the fact that river systems deliver corridor functionality across vast terrestrial landscapes (Puth and Wilson 2001), the relative magnitude of interaction between humans and undomesticated species is high in river corridors, and interaction has relatively large potentials for carrying systemic and/or cascading impacts (Chapman et al. 2020). When considered in a broad interdisciplinary perspective, it may therefore be relevant to look at river corridors as spaces of high-density interaction between various entities, only some of which are human. These include intentional organisms (humans) as well as non-intentional organisms (flora, fauna) set in the context of abiotic entities (waterbodies, soils etc.) co-constituting a common environment through networked activities.

Established approaches to river corridor management include varieties of integrated water resource management (IWRM) (Biswas 2008), including the so called nexus approaches (Benson et al. 2015). The IWRM approach is old and well established, going back some 75 years. It is widespread and has strong global institutional foundations (UNEP 2014). It is considered widely as a roadmap towards higher levels of standardization, coordination and hence also globalization of otherwise messy, poorly documented and locally adapted approaches to water management, thus it reflects a prioritization of standardized methods and associated conceptual vocabularies over local ones. The main conceptual tenet of the approach is an ambition for integration of formerly discrete aspects of water management into a unified, balanced, holistic framework (UNEP 2012). However, the IWRM approach has been widely criticized for being unspecific due to its ambition of integrating multiple processual elements while standardizing associated concepts, which has led to increasing levels of abstraction making implementation difficult. At the height of its popularity, the record of things to "integrate" encompassed no less than 41 sets of opposite elements, ranging across diverse phenomena groups such as surface water and groundwater, economic supply and demand, local and regional scales, genders, and the administrative levels of institutions (Biswas 2008). Later criticism has focused on lack of contextual sensitivity and challenges relating to collaborative elements within IWRM, highlighting a need for more thorough "analysis of the local context and existing governance arrangements" (Watson et al. 2019). Recent work to provide an overview of variations in collaborative processes 
included within IWRM have illustrated that these challenges may be correlated with ambitions to achieve standardized vocabularies describing and codifying actor and stakeholder contributions (see Galvez and Rojas 2019). The Nexus approach, which in its current form was defined as an alternative to IWRM (Pahl-Wostl 2019), is predicated on an ambition to (1) closely integrate otherwise disparate sectors of society depending on the same water resources, such as agriculture and urban water usage for example, and (2) form the basis of cross-sectoral policy integration focusing on ensuring stakeholder involvement, equity and sustainability (Pahl-Wostl 2019; Waughray 2011). As such the Nexus approach is similar to IWRM in many respects, but has been characterized by a broader more explicit "multicentrism" with respect to integrating policies and stakeholder groups related to water management on equal terms (Benson et al. 2015).

Taken as whole, the multitude of local and regional scale approaches to water management included under the headings of IWRM and Nexus approaches exhibit a range of common challenges. These include:

(1) A focus on standardized ontologies: Establishing standardized, context-independent ontologies defining which sectors, processes, stakeholders, policies etc. to include within water management deliberations. This may have the effect that IWRM approaches become less agile and less adaptable to local conditions, and that local stakeholders, processes and other entities of importance are overlooked in cases where they do not fit pre-defined ontologies.

(2) A focus on exogenous intervention strategies: Introducing processes of decision making, which are designed elsewhere into local contexts. This includes the implementation of global and/or universal sustainability targets into contexts where other targets exist. These types of collaboration may risk institutionalizing an asymmetry between local decision making practices and more powerful external policy regimes.

(3) A focus on imposing order: Maintaining a view where models employed to represent and predict phenomena and practices involved in water management follow logical rulesets emphasizing clarity and transparency, rather than adapting such models to messiness, emergent properties of the systems studied, unexpected modes of organization encountered, inherent complexities, insecurities, incoherence, and fragmentation. This may compromise the precision and local relevance of models and analysis efforts.

Based on the observations outlined above, we hypothesize that to manage river corridors in a sustainable way, it may be helpful with an approach which ontologically side-lines humans with other entities and explicitly addresses ontological complexity. This invites landscape ecological analyses to go "beyond the study of either social or ecological networks", and instead focus on what Nabavi and Daniell (2017) have referred to as "the heterogeneity of the real world" where "all entities are treated symmetrically and the world of non-humans embraced". Spinoza's ethics offers the first written account of such an approach within philosophy (Spinoza 2001) and within Science and Technology Studies, hereunder Actor-Network Theory (ANT), it has come to influence numerous disciplines including economics (e.g. Callon and Muniesa 2005) and political theory (e.g. Latour 2004). On this basis, recent decades have seen a proliferation of so-called flat ontological approaches (Joronen and Häkli 2017), and their applications within landscape ecology and cognate disciplines is no rarity (Christensen et al. 2017; Pries 2018).

Murdoch (1997) suggests the deployment of a flat ontological approach allowing symmetric treatment of entities, a so called "geography of associations", to overcome dualisms such as micro/macro, subject/ object or particular/universal known to force scholars to shift registers and tools when analyzing complex ecosystems where actions are both local and global at the same time. Marston et al. (2005) proposes to eliminate the use of hierarchical concepts of scale in human geography altogether and deploy a networked ontology, as they are "convinced that the local-toglobal conceptual architecture intrinsic to hierarchical scale carries with it presuppositions that can delimit entry points into politics - and the openness of the political - by pre-assigning to it a cordoned register for resistance." The points raised by Marston et al. (2005), sparked a heated discussion in the scientific community (see e.g. Leitner and Miller 2007). 
Recent contributions to this line of thinking are often labelled as 'more than human geographies' (MTHG), and are characterized by close attendance to nonhuman agency, focusing on ways of representation that escape predominantly human-centered analysis and argumentation (Isaacs 2020; Lorimer 2015). Attention is on multispecies encounters and conflicts, with an emphasis on including marginalized human and nonhuman actors, whose voices often go unheard. However, encounters with nonhuman actors in itself has not been found to increase multispecies empathy, wherefore, Pitt (2018) identifies a need for defining topologies of nonhuman-human interaction. In another contribution, Ash (2020) argues for the need to consider the form of entities when deploying flat ontologies in geography as things are not necessarily reducible to their relations. In this view, more-thanhuman-geographies coupled with political ecology could "help track the political and economic beneficiaries of different multinatural futures", and thus could prove a useful tool towards ensuring environmental justice.

In addition to catalysing alternative inquiries, this line of reasoning has caused a politicizing of nature. In his book Politics of Nature (2004), Bruno Latour presents an original way of understanding the interface of science and politics, inspired by ANT, which he calls experimental metaphysics. Latour (2004, p. 233) defines politics as 'the progressive composition of a good common world' and states that political philosophy is obligated to include all those things that have been marginalized and/or excluded from politics up until now (Latour 2004, p. 58). He goes on to compare the notion that nonhumans should be excluded from the political sphere with histories of segregation, speculating that we may come to a point in our biophilic development where it will seem obvious to compare current species-centric political activity to parallel histories of racist and sexist political exclusion (Latour 2004, p. 69). "Latour convincingly argues that the adoption of an experimental metaphysics and the attempt to sensitize the collective towards unexpected transformation are excellent ideas. Yet, it remains totally opaque how such a generalized change in outlook could conceivably be brought about" (Bruun Jensen 2006). To explore the implications of bringing about such flat political philosophy, Raffn and Lassen (2021) operationalized Latour's politics of nature through the design of a series of deliberation and decision making methods called "politics of nature" $(\mathrm{PoN})$, which inspired the experiment reported in this article.

We hypothesize that the effect of applying PoN for collaborative engagement with stakeholders within landscape ecology and cognate fields will be tremendous if the methodology works as intended and is able to shift and relativize ontological perspectives held by stakeholders in in-situ discussions. We here report on an experiment testing this approach, in the form of a collaborative water management project designed to identify new ways of overcoming the conceptual and methodological challenges characteristic of current IWRM approaches detailed above. The experiment was conducted in 2020 in the Eerste River Catchment in South Africa, where we tested "politics of nature" $(\mathrm{PoN})$ as an alternative approach to collaborative involvement of stakeholders in water management. Building on the theoretical notions of a "flat ontology" that deviates from the IWRM/Nexus approaches identified above; our experiment sought to answer the following research questions: (1) How transdisciplinary alignment of complex ontologies emerging from a collaborative process could be mediated using the PoN participant deliberation scheme, (2) How a contextualized account of the collaborative process could be extracted from ethnographical data collected systematically during a facilitated collaborative process, and (3) How a shift of authority from researchers to participants with respect to defining ontologies would contribute to transforming the collaborative process.

\section{Methods and materials}

A method for conducting collaborative deliberations about natural resource management was developed in accordance with the methodology of "politics of nature" (PoN) outlined by Raffn and Lassen (2021). PoN rests on the notion of a flat ontology, meaning that "humans, things, plants, animals, feelings and concepts" are all considered equally as beings. As such, the approach equals humans ontologically with other beings present in the landscape, highlighting that "what is common to all beings is that they express themselves through their...associations with other beings. Some can speak by themselves; others require spokespersons to articulate their positions" (italics in 
original). In this perspective, humans enjoy no more rights than other things, but are tasked with representing beings who cannot speak for themselves. They do so as their ambassadors, and often participants will need to represent many beings simultaneously. On this basis PoN-methodology stresses a perspective where all beings are included in political processes, shifting governance perspectives to a focus on collectives of beings rather than human societies alone. Tp achieve this, participants are assigned skill sets (roles) according to the PoN methodology, meaning that each participant must undertake particular procedural tasks in the conversation, including acting as spokespersons for various groups or types of beings, critically assessing the argumentation of others etc. In this way participants are gradually empowered to champion the process and given impetus to relativize traditional ontologies while including a broader selection of beings in deliberations. The PoN process evolves iteratively over a series of sessions, each comprising four stages. In stage 1, beings and spokespersons are identified. In stage 2, they are associated together. In stage 3, their situated perspective including ideas, motivations and proposals are explored. In stage 4, potential effects of the proposals on all beings are evaluated and it is assessed if proposals can be implemented. At the turn of each session participants are asked to challenge and reform the process to better suit their needs. Further details of the application of this method are given in "Analogue sessions", (see Raffn and Lassen 2021 for a more comprehensive description).

The PoN methodology was adapted and implemented in an experiment with decision making in the Eerste River catchment in South Africa, where it was used as a transdisciplinary research tool to establish information about current water management practices and challenges experienced in this context. A digital data capture platform was designed for the project and used to enable structured collaborative data compilation and subsequent analysis efforts. To this end, a graph-database was constructed to enable analysis and visualizations of the data.

\section{Case area}

To experiment with PoN-methodology in the context of watershed management, we tested its usefulness in a case area in South Africa: The Eerste River catchment (see Fig. 1). In South Africa water resources are governed at national level through two complementary acts of parliament: the National Water Act (RSA 1998) and the Water Services Act (RSA 1997). At a national level, the National Department of Water and Sanitation is the custodian of water resources and is ultimately responsible for water resources and ensuring South Africans have adequate drinking water and sanitation. National Government delegates water resources management to Catchment Management Agencies (CMAs) who in turn organize local scale Water User Associations (WUAs), providing a basis for local scale IWRM processes. Depending on the setting, WUA members can include farmers, municipal representatives, industries and other stakeholders. However, in most South African catchments (except two) the country's water management system failed to implement independent multi-level governance systems, largely due to institutional barriers and inwardfocused governance approaches in key institutions. In this context the Stellenbosch River Collaborative was set up in 2014 to experiment with alternative governance structures in the Eerste River Catchment (Büchner-Marais 2016). Based on these experiences the so-called "Collaborative governance organization" (Co-Go) was instituted as an NGO offering a transformative collaborative governance framework based on a bottom-up inclusive stakeholder approach to address water security jointly for collective benefit. It is from this network that the inquiry into ensuring water security using PoN departed (Collaborative Governance 2020).

\section{Collaborative data collection process}

The collaborative data collection process was started in February 2020 at Stellenbosch University. A group of 12 informants took part in the process, which took place over a series of recorded analogue and digital meeting sessions. The purpose of the meetings was to understand the myriads of worlds that make up the Eerste River and provide a due process enabling that these potentially differing worlds could be tied to common frames of reference by collaborately constructing ontologies. To reduce priming, the first PoN session was initiated by asking 'what affects the wellbeing of the Eerste River and why?'. Thus only the existence of the Eerste River and its status as threatened was ontologically established a priori. For 


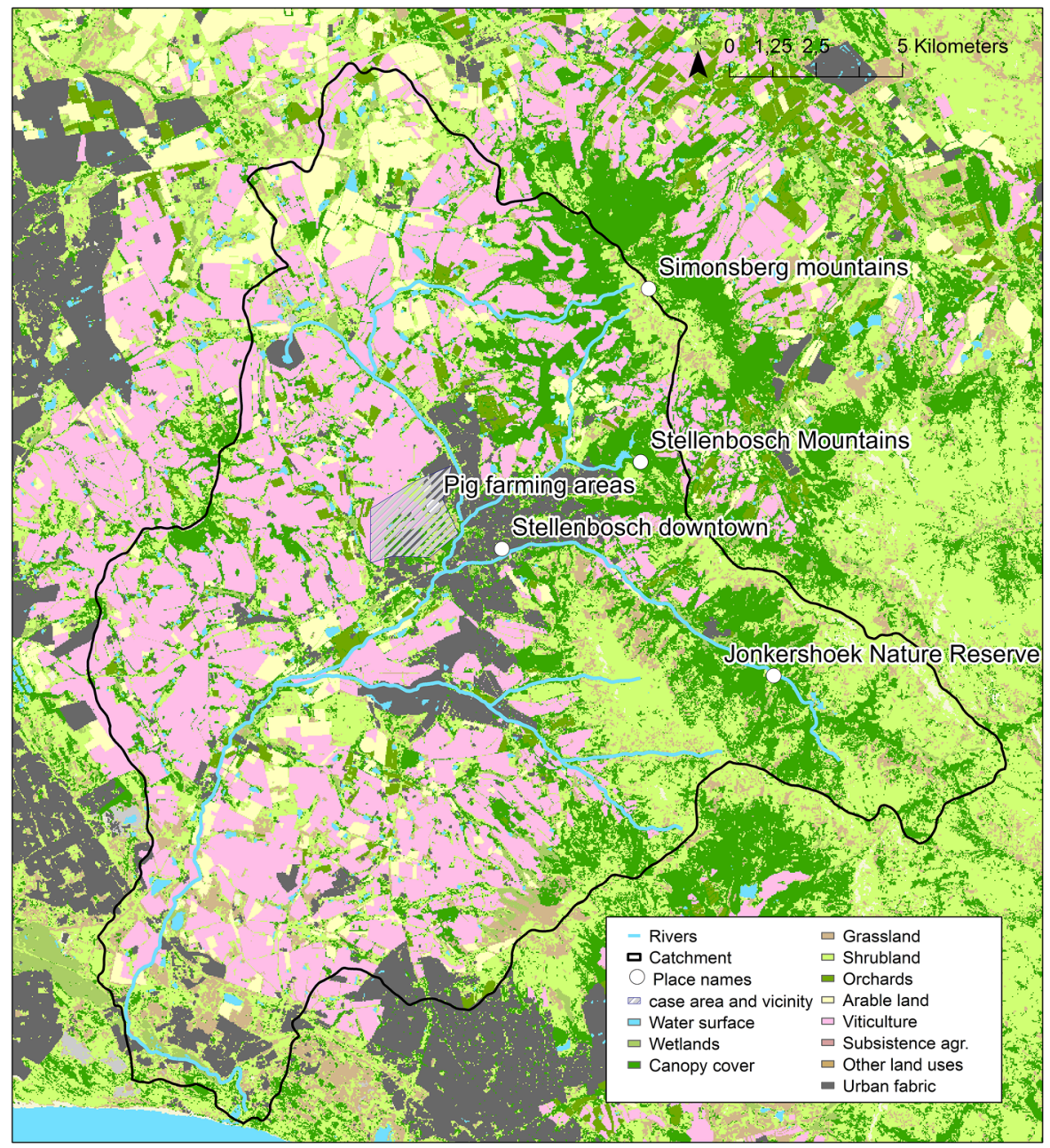

Fig. 1 Location of the case area within the Eerste River Catchment, South Africa (South African National Land-Cover (SANLC) 2013)

the subsequent sessions, participants were informed via mail on the topic and scope of the PoN session, which were decided upon or derived from the previous sessions.

\section{Analogue sessions}

Analogue sessions started by assigning skill sets (roles) to participants, after which a conversation was mediated, focused on identifying beings that participants found relevant to understanding the existence of Eerste River and who was understood to have direct or indirect associations with it. Participants then qualified their associations with the identified beings and were assigned ambassadorships in accordance to the perceived strength of their associations and capacity to represent the beings. Concurrent with the qualification of ambassadorships, qualified ambassadors not present at the table were identified. These two approaches of expanding the inquiry (an expansive topic: the beings included; and an expansive informant group: the ambassadors deemed necessary to represent these beings) are examples of the type of snowball sampling used, whereby conversation with one group of informants forms the outset for identifying further informants (Bryman 2016). This ensured a larger coverage of the beings in the catchment. Ensuring that the participants were free to decide which beings and representatives to identify was regarded more important to the experiment than to control sampling bias. When identifying missing representatives, the participants had to make the 
reasoning for their desired inclusion explicit, thus enabling potential bias to be analyzed. In order to determine when the dataset could be regarded as saturated, we operationalized Latour's (2004) notion of the learning curve, with inspiration from the accumulation curve applied in fuzzy cognitive mapping (Özesmi and Özesmi 2004). The X-axis depicted the number of rounds and the $y$-axis the accumulated number of beings. A two-round running average increase in identified beings of less than 5\% (Raffn 2020) was set as the saturation threshold, at which time further inquiry is to be terminated.

\section{Digital sessions}

Digital sessions were carried out on Skype using the built-in recorder. After evaluating the analogue sessions, it was decided that the virtual sessions would focus on having participants provide narratives of the catchment and the issues that they found important to articulate, and have the inquiry extend from the narratives. While participants provided narratives, beings and their representatives were typed in to a custom-built digital interface (see below). Following an initial analysis of the data collected digitally, the participants were invited to a virtual seminar where the findings were shared and feedback obtained.

\section{Design of digital platform}

Data capture was done by custom-building a digital platform using the web development application Jam.py (Jam-Py 2020). This enabled rapid prototyping of both back-end database and front-end interfaces. Forms for data entry were created and tied together in the relational SQLite data structure. Figure 2 illustrates the data structure employed in the database, which was designed to capture understandings of relationships between beings, ambassadors and associations in the dataset. The jam.py prototype was hosted online and participants could enter, but not edit or delete information. To create a structure aligned with the flat ontology we chose to use the graph data structure. Graph data consists of nodes (or vertices) linked by edges, which can be seen as analogous to beings linked by associations (see e.g. Nabavi and Daniell 2017). The data from the SQLite relational database was thus structured for input into ArangoDB, a native multimodal database supporting graph data structures (ArangoDB 2020).

\section{Data capture}

Recordings of the sessions were transcribed and participant names replaced with pseudonyms. The transcriptions were done in Microsoft Excel 2016. Each articulation was labeled with a timestamp and a pseudonym to identify the speaker. The transcriptions were then sent back to the participants who confirmed that they could be used in the public-facing webapplication. In the analogue sessions, the participants (ambassadors) filled out physical forms (handouts) that were digitized afterwards. In digital sessions, participants entered it into the database directly.

The experimental dataset reported here should be considered a work in progress. It was interrupted intentionally to allow us to investigate the theoretical and methodological implications of using experimental PoN methods in landscape research before upscaling the method further. Data collection processes were frozen at the time of writing to be able to report and reflect on the dataset itself, in an effort to outline what its introduction adds to conventional types of land use survey materials within integrated water resource management.

\section{Data analysis}

The accepted transcriptions were imported into ArangoDB and unique keys generated and exported. A custom-made python script searched for being names in articulations, and created edges between these when found. Linking participants (ambassadors) with articulations, and articulations with beings, enabled creation of graph networks where the position of ambassadors within the network could be visually inferred. Linking beings directly with articulations (with articulations represented as edges), enabled creation of a network of beings solely from articulations. ArangoDB's query language allowed the graphs to be traversed so that beings with direct and indirect associations with one another could be identified.

Based on the database described above, a series of text narratives were synthesized, in an attempt to convey perspectives on the river held by the informants. The approach was designed to re-narrate the reality of the Eerste River based directly on 


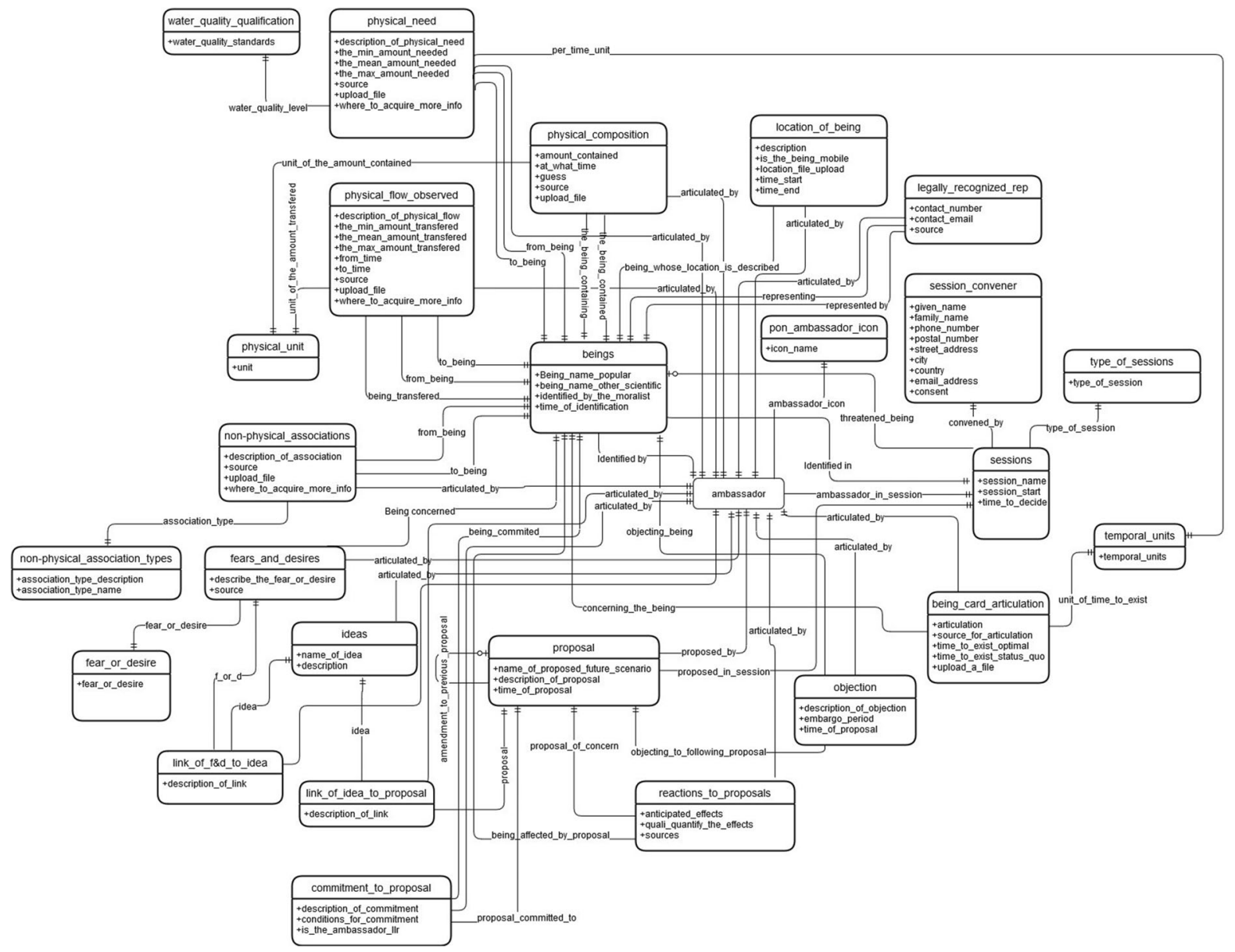

Fig. 2 Diagram showing the data model used for the digital data capture system. The data model shows the relationship between all variables collected and stored in the database created for the project

articulations stored in the database, highlighting key points of agreement and key disparities with respect to ontologies, histories and utilities of the river and its associated beings. Reference numbers enclosed in parentheses are used in the text to refer to articulations (data points) in the database (Fig. 3). These links are found in Appendix 1.

\section{Results}

Overview of the dataset: a relational database of associated beings present in the watershed

A total of 12 unique informants partook in 10 sessions. In total, the interviews produced 1059 articulations in which 235 individual beings (plants, animals, persons,
Synthetic narrative

The area where pig farming set in initially is now completely changed, and there are problems with manure floating in rivulets through the Enkanini (38).

The issue was discovered by Wild lands (a conservation NGO). However, as Wildlands had no mandate to resolve the issue (39) local and regional authorities were alerted. They inspected the site (40) but the issue fell between desks (41), or there simply were not enough resources to address the issue (42).

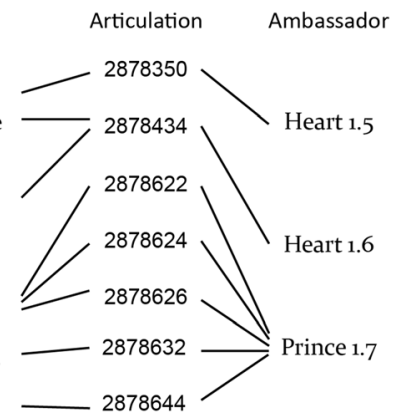

Fig. 3 A sample of data from the project database. The sample illustrates how narratives were synthethized from articulations, which in turn was linked to the ambassadors making them. See Appendix 1 for a list of the transcribed articulations

groups, populations and ecosystems etc.) were identified by the informants in conversation. The number 
of beings identified in each session is depicted in Fig. 4, and it is clear from the visualization that the predetermined degree of saturation was not reached. The derived dataset consists of a graph database detailing the beings articulated by the interviewees (represented as nodes) and articulated associations between beings (represented as edges between nodes) forming a semantic web emulating ecosystem complexity as it is understood politically by the interviewed stakeholders (the informants). Of the 235 identified beings, 128 were considered widespread in the catchment while 107 were related to specific spatial subsections of the catchment. Of the total 235 beings, 66 were associated directly (spatially and/or functionally) with the Eerste River ecosystem understood in any of the meanings attributed to it by the participants. Another 126 beings were indirectly related to the river through one or several links of association (for example through a food chain, dependency on a related resource, being related to the same location, production system, ecosystem or land use etc.). 46 of the identified beings were identified as humans while 69 were nonhuman and 119 were collectives comprising both human and nonhuman beings (for example farm production systems, ecosystems etc.). With 235 beings, a potential of 27,495 possible sets of unidirectional associations existed in the database, out of which 963 sets of associations were expressed in the articulations made. The snowball sampling employed led to the in-situ identification of 10 additional informants (referred to as ambassadors), whose accounts were deemed necessary to further nuance the account of the Eerste River case area according to the informants (see Fig. 4).

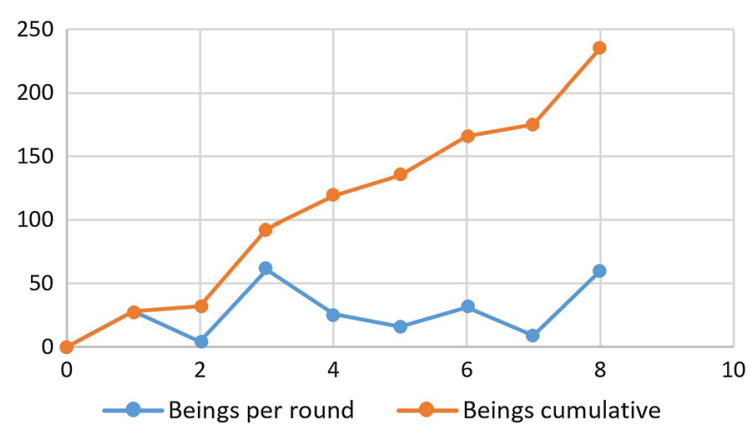

Fig. 4 Beings identified per round (blue) and cumulative beings (orange). The inclination of the curve has not flattened, and hence the dataset cannot be said to saturated
Table 1 below provides an overview of the dataset. Figure 5 illustrate its networked structure where each line represents an association and each node a being. A dataset such as the one reported here can be represented in a wide variety of ways. In the sections below, we first report on database structure and key characteristics of the network formed, illustrated through the use of a graphical network diagram highlighting relative degrees of contagion in the network ("The Eerste River represented and analyzed as a network entity"). We then move on to employ a storyline approach, narrating key relationships in the data from the point of view of the collective of beings. Section "Synthetic narratives derived from the database of articulations" consists of a series of such narratives building on the articulations collected, synthesizing them into a multi-vocal political account of the Eerste River.

The Eerste River represented and analyzed as a network entity

As a politically disputed resource which is critical to a range of economically, and socially important ecosystems, the Eerste River is subject to a wide array of differing and partly overlapping accounts of its nature, characteristics, ecology and utility. Its ontology is contested and multi-vocal-encompassing the combined reality experienced by a multitude of humans and other beings. While some beings must be anticipated to exist outside the interest sphere of humans, many beings receive enough attention from humans to become articulated in discourses about the river and its ecosystems. These articulations about the reality of their landscape given by people, form a complex network of empirically founded statements. While traditional water resource management approaches

Table 1 Overview of dataset

\begin{tabular}{lr}
\hline Elements of the dataset & $\#$ \\
\hline Informants interviewed & 12 \\
Articulations recorded & 1059 \\
Beings articulated & 235 \\
Associations articulated & 963 \\
New informants identified & 10 \\
\hline
\end{tabular}




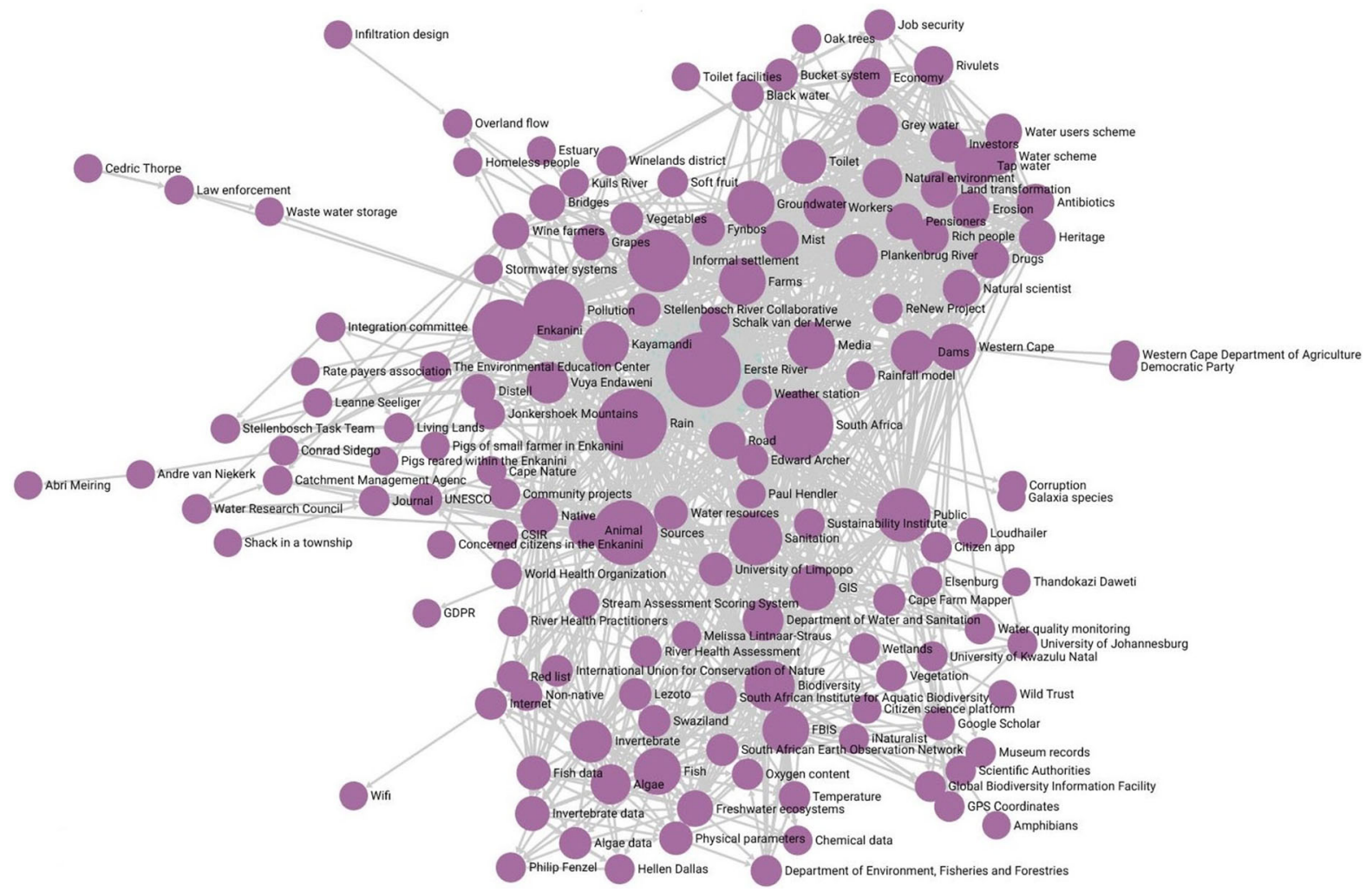

Fig. 5 Graph showing the variety of beings articulated in the dataset (purple dots) associated directly or indirectly (grey lines) with the Eerste River. Descriptive phrases from the database representing key features of the identity of the beings are shown

have sought to integrate such statements as perspectives of a common reality, by aggregating and reclassifying them within master-ontologies based on standardized vocabularies and flowchart models (UNEP 2014; Watson et al. 2019), we here approached the complexity of defining the nature of the river, by allowing categorizations and groups to emerge from the empirical context by assessing the frequency of their of articulation (see Raffn and Lassen 2021). With respect to the first research question, our results indicate that:

(1) The data collected does form the type of interrelated network we expected would exist. Observations recorded in the database form a dense web of shared ontological reference points, organized as a network (see Fig. 5) exhibiting a large degree of connectivity between nodes, with ontological variation in the material evident. Incongruent accounts can as black text (quotes). Areas with high relative densities of association between beings are shown as grey surfaces, interspersed by white surfaces at degrees relative to association density

be seen to connect with each other through numerous indirect associations in the network structure. Rather than seeing a pattern of several isolated, fragmented clusters of ontological statements we see a cohesive whole exhibiting varying levels of disagreement on definitions of the reality of the Eerste River catchment. This indicates that a relational, network oriented data collection approach is relevant to the phenomena studied, and that the PoN method employed is appropriately scaled and focused to capture and represent data of this kind.

(2) Despite the fact that viewpoints on the river form an interconnected mesh, disparities and disconnects can also be clearly identified, indicating that the dataset can be utilized to identify key points of disagreement. This is visible in Fig. 5 where the Eerste River forms the center of the graph (146 associations) and is surrounded by beings that are understood by the 
informants to influence its existence the most. These are precipitation patterns (130 ass.), informal settlements (106 ass.) and pollution (104 ass.). In the graph, the adjacency of beings is determined by the number of articulated associations and two general clusters can be seen. The lower part of the graph concerns monitoring and assessment of river health and the upper part concerns the beings whose existence are more closely entangled with Eerste River. This indicates that two parallel, but partly interconnected realities of the Eerste River coexist among the informants. This is further unfolded in Fig. 6, which shows clusters of relative agreement regarding ontologies between participants (ambassadors). It further indicates that the PoN method may be used to investigate such graph patterns, for example by calculating density metrics, focusing in on areas of high or low degrees of network contagion etc.
While such additional analysis fall outside the boundaries of this article, it is clear from the dataset we produced that there is a potential to support more focused, multi-scale analysis approaches.

Synthetic narratives derived from the database of articulations

The narrative below represents a curated account of water management and associated land use patterns in the Eerste River Catchment and especially around the informal settlement of Enkanini. In retelling the narratives of the Eerste River, we focused on providing an overview of the ecology of the river, and subsequently emphasized beings and associations which the informants deemed undesirable and detrimental to beings depending on the river-ecosystem. Other narratives could have been brought forward

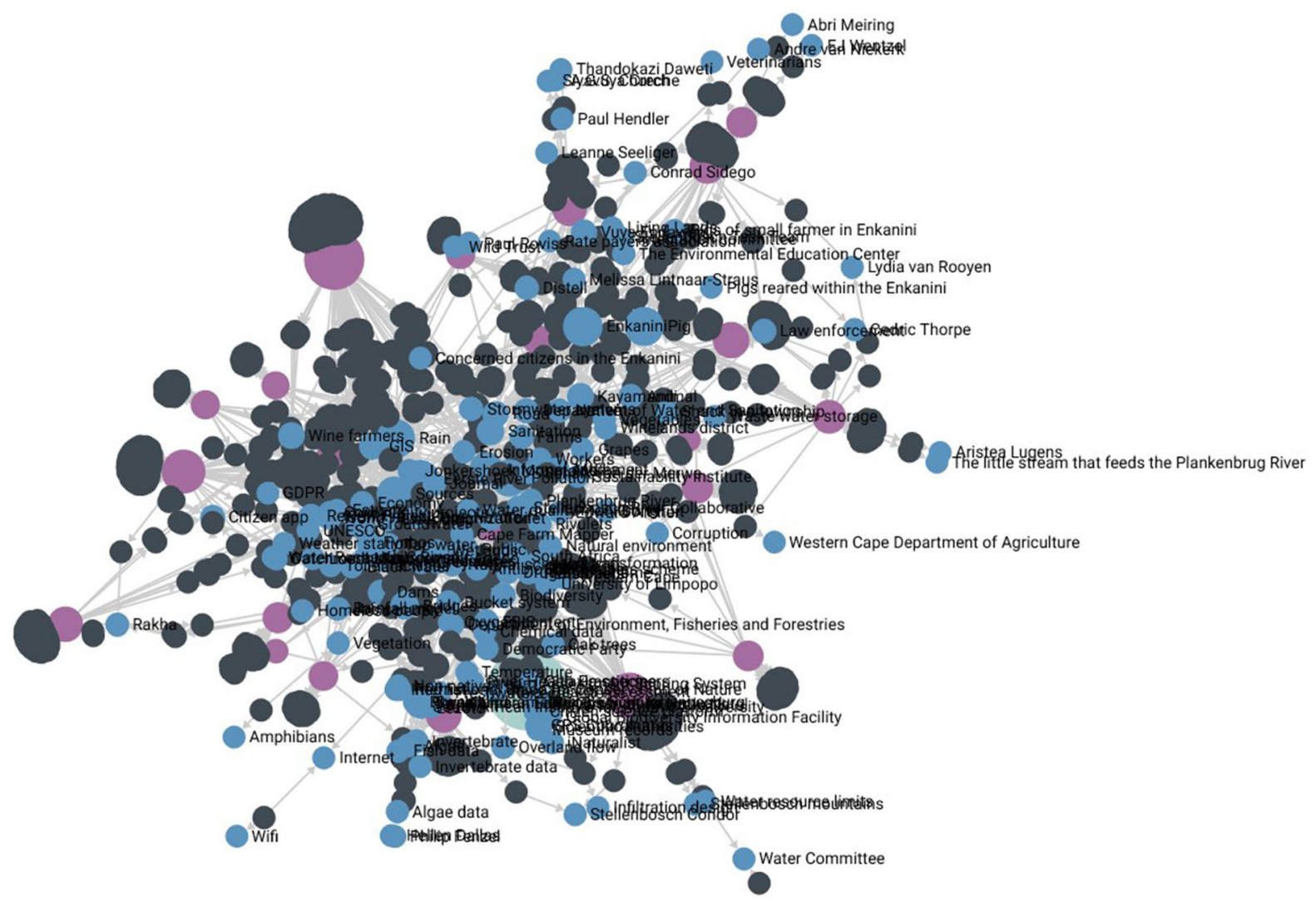

Fig. 6 Graph showing the ambassadors (pink nodes), making articulations (black nodes) that are first tying ambassadors and beings together, but also serve as bridges between beings. The graph position of the ambassadors can be understood as their position relative to the ontologies expressed by other ambassadors in the web of beings defined 
based on the rich material in the database. The numbers in parentheses refer to Appendix 1, where they link the synthesized narrative to the articulations upon which it is based.

\section{Delineation, identity and character of the Eerste River and its catchment}

The Stellenbosch Mountains, The Jonkershoek Mountains and the Simonsberg Mountains form the sides of the Eerste River catchment (1). Eerste River has its springs in the pristine Jonkershoek Natural reserve. As it flows through the landscape towards the sea, it is subjected to various land uses, which each contribute with a set of pollutants and wastes (2). Right after the nature reserve, it reaches the Jonkershoek Dam and here trout-farming starts. Moving downstream the river flows through agricultural areas with pesticide runoff affecting the river. This is the largest concern of Cape Nature, the nature conservation agency under the regional government. This goes on for the next few kilometers before it reaches Stellenbosch, where storm water drainage enters the river (3). Once the river passes through the old part of Stellenbosch, it reaches the confluence of the Plankenbrug River, which flows past the informal settlement Enkanini. Plankenbrug is considered an open sewer (4). Before the Plankenbrug meets the Eerste River it is joined by the Krom River, which in turn dilutes the pollution (5). A few kilometers further downstream, it meets with the non-perennial Veldwachters River, on which there is a wastewater treatment plant servicing 170-180.000 people (6). Interestingly, the pollution of the Eerste River is diluted significantly by the discharged wastewater (7). This shift between pollution and dilution is repeated as the river meets with its several tributaries until it reaches the coastline. From a management perspective this necessitates a very localized, context specific understanding, given that conditions in some places change every few hundred meters (8). Upon visual inspection, you will find floating debris in the Eerste River (9), and high counts of e-coli, drug residues, and human pathogens (10) have been documented (11). This pollution can be tracked back to the Enkanini (12) and causes health issue for the inhabitants living near the river, and environmental consequences downstream (13). The fish tell an important story from within the river, here more than half of the sampled taxa are non-native and one micro-endemic fish species, Pseudobarbus burchelli, is critically endangered. However, there are currently too few records to make qualified management decisions with respect to fish populations (14).

\section{Climate and water-the context of the river system}

From the National Master Plan for Water Management it follows that South Africa has a semi-arid climate, with an average annual rainfall of $465 \mathrm{~mm}$ and high variability in precipitation (15). However, weather stations are scarce and models are not localized. Hence, rainfall data and projections are inaccurate for the Eerste River Catchment (16). The Eerste River forms part of a larger water supply system and is artificially maintained, and the water released may come from Theewaterskloofdam or the Berg River dam in adjacent catchments (17). Groundwater is the primary water source for Stellenbosch with a daily extraction of 45 million liters (18). Dammed water is the other critical water supply (19). While the amount of dammed water is known, the amount of available groundwater is unknown and hence it is difficult to establish water resource limits (20). However, the understanding is that the groundwater is under severe stress (21) from both extraction and pollution (22).

\section{Relationships between the river and adjoining human formal and informal settlers}

The human population in Stellenbosch is extremely polarized, with affluent first world housing next to slums (23). The presence of informal settlements is considered a societal failure (24) that in turn causes societal problems on many levels (25). There are 14 informal settlements in Stellenbosch municipality, however focus in this survey experiment was directed towards the Enkanini, an informal settlement which emerged around 2004 as an overflow of the Kayamandi district in Stellenbosch (26). There is no infrastructure to get rid of waste (27), the households are not connected to water and sanitation and the current density of the houses makes it very difficult to provide such infrastructure (28). There are communal taps and toilets, but these are often vandalized, actions that appear to be coordinated by political factions (29). The socio-economic conditions within the Enkanini mean that it is unsafe to use public facilities at night. This lack of security, combined with a lack of 
sanitation results in the use of a 'bucket system' (30) where people's night pots are emptied out in the street or in the storm water systems (31). Enkanini is situated on steep slopes (32) so following rainfall events, the night soil along with water from washing of clothes is transported through rivulets and storm water systems to the rivers (33).

In 2014, it became evident to the informants that pigs farmed inside Enkanini were a factor relevant to the health of the river, and that fences to the adjacent nature reserve had been broken down (34). The farming encroachment on the Papagaaiberg Nature Reserve (35) is a threat to the micro-endemic plant species the Aristea Lugens (36) and the Renosterveld already critically endangered by the extension of vineyards in the area (37). The area where pig farming set in initially is now completely changed, and there are problems with manure floating in rivulets through the Enkanini (38). The issue was discovered by Wildlands (a conservation NGO). However, as Wildlands had no mandate to resolve the issue (39) local and regional authorities were alerted. They inspected the site (40) but the issue fell between desks (41), or there simply were not enough resources to address the issue (42). At the time of discovery, there were about 10 pigs in the area and one farmer (43). According to a recent report, there are now 5-12 farmers rearing approximately 300 heads of pigs, with each pig sold for approximately 3000 Rand, which constitutes a substantial income for the community (44). The pigs are slaughtered in the open and it is suspected that the intestines are fed back to the pigs (45). The meat is sold from the back of a Bakkie (light vehicle) with flies moving between the meat and night soil thrown nearby (46). Combined, these practices greatly increase the risk of zoonosis, of which covid-19 is the latest grave example (47). The first pig farmer in the area is quoted for saying that farming was his only way of making a living, and if an alternative location was given or another job provided, he would give it up (48). This is a widespread perspective, highlighting that "We can't expect of people to understand why we need to keep a nature reserve pristine and not build there and not hunt there and not pig farm there, if they can't make a living" (49).

When the township of Enkanini emerged, it created a wedge between the people living around Papagaaiberg and gave rise to a resurgence of black-white rich-poor social tension (50). The neighborhoods were divided into disparate districts, with middleclass people living in Onder Papagaaiberg and less affluent social groups living in Enkanini and Kayamandi (51). Where the former is concerned about impacts on property prices, the latter worry about finding jobs and housing (52). While the formal settlers do not want the informal settlers next door, most of the domestic workers come from there. They come to clean the houses and toilets and return to their shacks that do not have running water (53). Geographically the area is enclosed between Middelvlei farm on the north and industry and business districts such as Distell on the southern side (54). In 2006, the organization Vuya Endaweni, meaning 'Happy in this place', was founded (55). While the aim of Vuya Endaweni was to set up an environmental education center, the sole biggest concern for the people in Kayamandi and Enkanini was raising children 'while living in shacks' (56) and the biggest wish amongst women, was "someone to look after our children while we go look for work" (57). Therefore, a crèche called Siyavuya was opened, and its management was eventually taken over by the community. Vuya Endaweni and subsequent initiatives has successfully created spaces for conversations across otherwise entrenched divides (58). Although Enkanini was illegally occupied, due to the South African constitution the people cannot be forcibly removed (59). As such the settlement is permanent in practice, wherefore it seems logical to many observers, given the many negative externalities of the settlement, to raise questions such as 'why don't you put toilets there? Or why don't you put a skip there?'. However, the municipality is understood not to be allowed to intervene as the settlement is not on municipal land (60). In contrast to the official system, people living in Enkanini are organized through street committees; the internal workings of which remain unclear (61). Where municipalities are organized around wards, Enkanini being part of Ward 12, street committees are part of an alternative structure (62). Partly due to this state of affairs the area is not well policed; and when crime occurs, victims are understood to be supposed to consult the street committee before taking it to the police (63). This is seen as "restitute justice rather than criminal justice" (64) where it is described as being seen in some circles as acceptable to make a deal after you have commited violent crime (65). 
Wine farming depending on and affecting the river

Vineyards and viticulture is a widespread land use in the watershed, providing an important source of income and employment for the region, not least to the inhabitants of the informal settlements (66). According to on-farm studies, wine farmers appear to be the largest polluter of the groundwater and agricultural pollution can be witnessed along the entire Eerste River (67). The wine industry is in turn very affected by pollution (68) and relies heavily on access to sufficient water at an acceptable quality (69). If grapes are found to contain contaminants this is expected to have major repercussions on international markets (70).

\section{Discussion}

Our analysis of water management around Enkanini on the Eerste River indicate that issues impeding water security revolve around disparities in privilege, which makes the collective very complex to govern. Lack of infrastructure in the informal settlement Enkanini currently leads to severe pollution of its immediate environment. Animal rearing inside and next to the Enkanini further fuel this complex problem, creating spillover effects on human health, with strong feedback mechanisms linking land use practices with pollution and health issues. Pollution is transported downstream from Enkanini, via rivulets and the Plankenbrug River into the Eerste River. This has led to cascading degradations of systems crucial for a wide variety of actors, including farmers who if their production is compromised will be unable to provide work for people in the informal settlements. Without infrastructure and alternative livelihood strategies, the informal settlers have little choice but to infringe on the living spaces of critically endangered nonhuman beings for subsistence. Simultaneously, public institutions lack legal mandate and authority to urbanize the area and provide physical and social infrastructure needed to break feedback cycles driving unsustainable land use practices to expand. Yet attempts at providing basic infrastructures have been unsuccessful due to mismanagement or deliberate vandalism, the reasons of which remain unknown. Based on the available data we interpret this as a kind of Marronage, where informal settlers see the government as illegitimate and exclusive, and oppose a system understood to have colonial legacies (Bledsoe 2017). In this perspective, the conditions of the Eerste River can be understood to be in a vicious circle, stabilized by historical, physical, racial, legal, institutional, political and economic lockin mechanisms. A state of affairs that is supported by and possibly also contributes to increasing disparity between the formal and the informal, the rich and the poor, and the white and the black. It is a case of physically intertwined yet politically separated worlds, where no party has the mandate to negotiate a common future, and no trusted forum for doing so exists. By building a dataset unrestricted by existing ontological assumptions (with the exception of the existence of the Eerste River), based on a method designed to integrate political and physical ontologies, it was possible to show empirically how such disparities take center stage in catchment management. The ubiquitous human-nonhuman associations effectively document the arbitrariness of the nature-culture dichotomy, along which fault lines of ontological differences form and how these affect attempts at collaborative land use planning. Further analysis of the data and further extensions of the data collection process are likely to contribute with increased comprehensiveness and precision with respect to these insights, potentially pinpointing exact processes and patterns of exchange involved in the co-creation of further disparities in the communities studied.

With respect to our ambition to test the application of PoN as an alternative approach to integrated water management, the narratives recorded here served as a potential outset for decision-making processes, hereunder collaboratively emerging ontologies. The narratives brought ontological agreements, conflicts and premises to light, and thus formed the basis for a clearer, empirically founded understanding of current affairs. In retrospect, this illustrates that the Eerste River is an example of different realities coexisting. For some township dwellers and businesses it is a free trash collector, for the endemic fish it is a living space, for the farmers a natural resource underpinning their economic existence. These ontologies are in conflict and to a certain extent mutually exclusive, while in other respects they are complementary. We find that the formulation of a comprehensive contextualized narrative allows the collectives involved to view themselves through alternative lenses, which in turn is 
a prerequisite for articulating desired future states and assessing ways of getting there.

Considered as a methodological experiment, the use of PoN-methods in the Eerste River catchment provided a 'flat canvas' where beings of all kinds could become part of a unified cosmopolitics, as described theoretically by Latour (2004). As such, PoN can be understood as a method designed to add a structured political-ontological toolbox into natural resource management (see Raffn and Lassen 2021), in this case water resource management. In this respect the method works by systematically inviting agents to recognize how their categorizations of the world compare to alternative ontologies present in the same space. In contrast, widespread contemporary approaches to Integrated Water Resource Management (IWRM) seek to establish order by imposing externally defined ontologies on empirical contexts (Waughray 2011). For example by classifying stakeholders into standard, discrete or overlapping groupings (owners, producers, managers, consumers etc.) by employing predefined categories of utility when estimating the relative use value of water resources (drinking water, irrigation water, greywater, water associated with specific ecosystem functionality etc.) or by the introduction of specific, normative perspectives on governance (Biswas 2008; UNEP 2014). In light of the case study presented here, such approaches to water resource management must be considered problematic with respect to potential implementation in areas similar to the Eerste River watershed. The imposition of externally defined ontologies aiming at 'saving the environment' for example, risk engendering further sociopolitical entrenchment. Such standardized processes are likely to divert focus to externally conceived issues, instead of enabling a sociality to emerge where humans view themselves as custodians of an ongoing collective sense making and planning process. So does the potential imposition of formal exogenous governance in societies where political legitimacy is linked to informal and/or decentralized structures of decision making (Enqvist et al. 2020). We consider it likely that areas such as the Eerste watershed here studied, which have strong colonial histories, will be particularly non-receptive to these types of approaches to resource management (see also Nelson 2003). To achieve effective and equitable water management in contexts like the Eerste River Catchment will require that collaborative approaches to sense making and target setting are further refined. If a transdisciplinary research approach is to be successfully deployed in areas characterized by distrust and animosity, it must be embedded in fora not hampered by the challenges summarized above (Marais 2016). CO-GO and Stellenbosch River Collaborative, with their record of accomplishment of bringing disparate stakeholders together (Collaborative Governance 2020), could provide suitable fora for commencing such experimentations in the case studied here.

One of the key characteristics of PoN-methodology is the way in which humans are seen as potentially ontologically equal to other beings. This is a critical component of the method, because it aids in enabling the recording and analysis of ontological questions raised both iimplicitly and explicitly by informants. This is achieved by not imposing a prioiri ontological claims and by placing informants in conversation roles designed to elicit reflection on ontological categories otherwise taken for granted in debates and exchanges of viewpoints. With respect to the task of ensuring equity and symmetry in the representation of humans and nonhumans, we applied the broadest possible definition of agency. Everything that is associated with beings present in the controversy being investigated was considered a being, and their associations were meticulously documented. This political-ontological methodology was found to succesfully supply a platform and format of conversation where participants accounted for all beings in the same terms, regardless of these being human, nonhuman or hybrids, thus facilitiating holistic conversation about ecosystem functionality.

\section{Conclusions}

Popular approaches to natural resource management, such as Integrated water resource management (IWRM), generally lack openness with respect to the political significance of ontological claims made by stakeholders. By introducing a structured approach to capturing, showcasing and debating ontologies, we provided an alternative to IWRM, where ontologies instead emerged from the empirical context. The application of PoN-methodology was found to successfully initiate this process. The methodology commences as a highly structured approach, to ensure 
non-standardized ontologies to be established discursively and captured by researchers using a graph database. In this way a priori categorizations were avoided, opening up a dialogue-form allowing informants to freely articulate their worlds. Concurrently, this supplied the researchers with stories that could be re-narrated to make sense of the underlying conflicts and disparities hindering successful water management in the case study of the Eerste River catchment. The re-narration of the ethnographical data collected, provided a nuanced contextualized account of the ontologies present and emerging. While the methodology was given at the outset, the iterative nature and built-in reflexiveness of the method meant that the participants shaped the transdisciplinary framework. This caused a shift of authority from researchers to participants, in that they defined both the ontologies at play and how these were to be identified and signified. As such, the experiments we conducted with PoNmethodology indicate that the new method may be a valuable addition to existing approaches used within landscape research, environmental management and planning to mediate, intervene with and investigate collaborative resource management processes. However, it is too early to draw any decisive conclusions on the effect of the experiment. In order to fully understand the implications of PoN-methodology for transdisciplinary landscape research more research is needed that includes target-setting, planning, execution and evaluation of interventions, in order to allow these evolving methods to be compared with existing alternatives at larger scales.

Acknowledgements The authors would like to thank Marius Snyman and Niels Faber for helping with setting up the digital version of PoN, and our respective workplaces for granting us the freedom to invest time in this endeavour. Finally, we owe a great thanks to all those that are part of the experiment.

Funding Funding was provided by Aarhus Universitet (Grant No. GSST Student Grant).

\section{References}

Albert JS, Destouni G, Duke-Sylvester SM, Magurran AE, Oberdorff T, Reis RE, Winemiller KO, Ripple WJ (2020) Scientists' warning to humanity on the freshwater biodiversity crisis. Ambio. https://doi.org/10.1007/s13280-02001318-8
ArangoDB [WWW Document] (2020) https://www.arangodb. com/resources/white-paper/coming-from-relational/

Ash J (2020) Flat ontology and geography. Dialogues Hum Geogr 10:345-361

Benson D, Gain AK, Rouillard JJ (2015) Water governance in a comparative perspective: from IWRM to a "Nexus" approach? Water Altern.--interdiscip. J Water Polit Dev 8:756-773

Biswas AK (2008) Integrated water resources management: is it working? Int J Water Resour Dev 24:5-22

Bledsoe A (2017) Marronage as a past and present geography in the Americas. Southeast Geogr 57:30-50

Boretti A, Rosa L (2019) Reassessing the projections of the world water development report. NPJ Clean Water 2:1-6

Brierley GJ (2020) The socio-ecological river: socio-economic, cultural and environmental relations to river systems. In: Brierley GJ (ed) Finding the voice of the river: beyond restoration and management. Springer International Publishing, Cham, pp 29-60

Bruun Jensen C (2006) Review essay. Experimenting with political ecology: bruno latour, "politics of nature: how to bring the sciences into democracy." Hum Stud 29:107-122

Bryman A (2016) Social research methods. Oxford University Press, Oxford

Büchner-Marais C (2016) Transformative collaborative governance towards sustainability: the case of the Stellenbosch river collaborative, $\mathrm{PhD}$ thesis. ed. Stellenbosch University, Stellenbosch, South Africa

Callon M, Muniesa F (2005) Peripheral vision: economic markets as calculative collective devices. Organ Stud 26:1229-1250

Chapman DS, Gunn IDM, Pringle HEK, Siriwardena GM, Taylor P, Thackeray SJ, Willby NJ, Carvalho L (2020) Invasion of freshwater ecosystems is promoted by network connectivity to hotspots of human activity. Glob Ecol Biogeogr 29:645-655

Christensen AA, Brandt J, Svenningsen SR (2017) Landscape ecology. In: Richardson D, Castree N, Goodchild MF, Kobayashi A, Liu W, Marston RA (eds) The international encyclopedia of geography. Wiley, Oxford, pp 1-10

Collaborative Governance (2020) Co-Go. Africa [WWW Document]. https://sites.google.com/centrex.co.za/cogo. Accessed 08 Dec 2020

Dayton GH (2019) Water availability. In: Fath B (ed) Encyclopedia of ecology, 2nd edn. Elsevier, Oxford, pp 656-662

Enqvist J, Ziervogel G, Metelerkamp L, van Breda J, Dondi N, Lusithi T, Mdunyelwa A, Mgwigwi Z, Mhlalisi M, Myeza S, Nomela G, October A, Rangana W, Yalabi M (2020) Informality and water justice: community perspectives on water issues in Cape Town's low-income neighbourhoods. Int J Water Resour Dev. https://doi.org/10.1080/07900627. 2020.1841605

Erős T, Lowe WH (2019) The landscape ecology of rivers: from patch-based to spatial network analyses. Curr Landsc Ecol Rep 4:103-112

Galvez V, Rojas R (2019) Collaboration and integrated water resources management: a literature review. World Water Policy 5:179-191 
He F, Zarfl C, Bremerich V, David JNW, Hogan Z, Kalinkat G, Tockner K, Jähnig SC (2019) The global decline of freshwater megafauna. Glob Change Biol 25:3883-3892

Isaacs JR (2020) More-than-human geographies. In: Richardson D, Castree N, Goodchild MF, Kobayashi A, Liu W, Marston RA (eds) International encyclopedia of geography: people, the earth, environment and technology. Wiley, Hoboken, pp 1-5

Jam-Py [WWW Document] (2020) https://jam-py.com/

Joronen M, Häkli J (2017) Politicizing ontology. Prog Hum Geogr 41:561-579

Latour B (2004) Politics of nature: how to bring the sciences into democracy. Harvard University Press, Cambridge

Leitner H, Miller B (2007) Scale and the limitations of ontological debate: a commentary on Marston, Jones and Woodward. Trans Inst Br Geogr 32:116-125

Lorimer J (2015) Wildlife in the anthropocene: conservation after nature. University of Minnesota Press, Minneapolis

Marais CLB (2016) Transformative collaborative governance relations towards sustainability: the case of the stellenbosch river collaborative, PhD Dissertation. ed. Stellenbosch University, Stellenbosch

Marston SA, Jones JP, Woodward K (2005) Human geography without scale. Trans Inst Br Geogr 30:416-432

Murdoch J (1997) Towards a geography of heterogeneous associations. Prog Hum Geogr 21:321-337

Nabavi E, Daniell KA (2017) Rediscovering social-ecological systems: taking inspiration from actor-networks. Sustain Sci 12:621-629

Nelson RH (2003) Environmental colonialism: "saving” Africa from Africans. Indep Rev 8:65-86

Özesmi U, Özesmi SL (2004) Ecological models based on people's knowledge: a multi-step fuzzy cognitive mapping approach. Ecol Model 176:43-64

Pahl-Wostl C (2019) Governance of the water-energy-food security nexus: a multi-level coordination challenge. Environ Sci Policy 92:356-367

Pitt H (2018) Questioning care cultivated through connecting with more-than-human communities. Soc Cult Geogr 19:253-274

Pries SJ (2018) A geographer looks at the landscape, once more: toward a posthumanist political ecology approach. Geogr Compass 12:e12401
Puth LM, Wilson KA (2001) Boundaries and corridors as a continuum of ecological flow control: lessons from rivers and streams. Conserv Biol 15:21-30

Raffn J (2020) Playing with societies' operating systems to ensure sustainable water use. Aarhus University, Aarhus

Raffn J, Lassen F (2021) Politics of Nature: the board game. Soc Stud Sci 51(1):139-164. https://doi.org/10.1177/ 0306312720983907

RSA (1997) Water Services Act (WSA), Act 108. Republic of South Africa

RSA 1(998) National Water Act (NWA), Act 36. Republic of South Africa

Spinoza B (2001). Ethics. Wordsworth, ware

Tickner D, Opperman JJ, Abell R, Acreman M, Arthington AH, Bunn SE, Cooke SJ, Dalton J, Darwall W, Edwards G, Harrison I, Hughes K, Jones T, Leclère D, Lynch AJ, Leonard P, McClain ME, Muruven D, Olden JD, Ormerod SJ, Robinson J, Tharme RE, Thieme M, Tockner K, Wright M, Young L (2020) Bending the curve of global freshwater biodiversity loss: an emergency recovery plan. Bioscience 70:330-342

UNEP (2012) Status report on the application of integrated approaches to water resources management. United Nations Environment Programme, Nairobi

UNEP (2014) Towards integrated water resources management-international experience in development of river basin organisations. United Nations Environment Programme (UNEP), Khartoum

Watson N, Shrubsole D, Mitchell B (2019) Governance arrangements for integrated water resources management in Ontario, Canada, and Oregon, USA: evolution and lessons. Water 11:663

Waughray D (ed) (2011) Water security: the water-food-energyclimate nexus: the world economic forum water initiative. Island Press, Washington

Publisher's Note Springer Nature remains neutral with regard to jurisdictional claims in published maps and institutional affiliations. 